\title{
Physical distance and sex in moderated groups: Neglected factors in small group interaction
}

\author{
MARTIN GIESEN \\ Mississippi State University, Mississippi State, Mississippi 99762 \\ and \\ CLYDE HENDRICK \\ Kent State University, Kent, Ohio 44240
}

\begin{abstract}
An experiment examined the effects of sex of subjects, sex of moderator, and seating distance between members of a small group on moods, evaluations, attraction, and attitude expression. Groups of three subjects and a moderator discussed a socially relevant issue and then made several ratings. During the discussion, group members sat either very close to each other or very far apart. The expectation that males would react unfavorably while females would react favorably to close seating was not obtained. Instead, sex of moderator interacted strongly with distance. Regardless of sex, groups were more positive close to a female moderator and far from a male moderator. Attitudes showed the same interaction. Interpretations were that (1) the ranking person helps define the spacing norms for a group, and (2) there are sex differences in "personal space."
\end{abstract}

According to a suggestion by Stokols, Rall, Pinner, and Schopler (1973), a person's demands and expectations for space are jointly determined by (1) physical factors (e.g., amount of available space, number of others present, physical constraints such as furniture arrangements), (2) social factors (e.g., nature of activity, situational norms, cultural norms), and (3) personal factors (e.g., sex, expectations of intimacy, liking, affiliative needs). The present research examined the interactive effects of the personal factor of sex and the physical factors of imposed interaction distance and moderator sex on feelings, evaluations, and attitudes in the context of group interaction.

Interpersonal distance research has been reviewed by Lett, Clark, and Altman (Note 1), with one conclusion being that close interpersonal spacing is accompanied by increased intimacy and friendliness (e.g., Byrne, 1961; Mehrabian, 1968), with the exception of extremely close distances (Dabbs, 1971; Dosey \& Meisels, 1969). Several studies have varied actual interaction distance in different experimental contexts (e.g., Argyle \& Dean, 1965; Freedman, Klevansky, \& Ehrlich, 1971; Giesen \& Hendrick, 1974).

This research was supported in part by an institutional grant to the first author from Mississippi State University. The authors wish to thank Dr. Richard Heslin for his comments on an earlier version of this manuscript. Requests for reprints should be sent to Martin Giesen, Department of Psychology, P.O. Drawer PF, Mississippi State University, Mississippi 39762. The authors are grateful to Dan Baskin, Sharon Coy, Al Lopez, and Linda Roberts. Each of the experimenters had experience in performing the role of moderator in at least one previous study. Thus, they were well practiced at the task and recognized the importance of maintaining standardized behavior in relation to one another and across all experimental conditions.
Sex differences in interpersonal distance have been reported by a number of investigators. Researchers employing social schemata (Meisels \& Guardo, 1969) reported a strong tendency for females to use more physical distance under unpleasant conditions than do males. Willis (1966) reported that women were approached more closely than men by members of both sexes. In general, speakers tended to stand closer to women than to men, and women stood closer to good friends and further from first acquaintances than did men (see also Baxter, 1970). A study by Jourard and Friedman (1970) reported that females reduced their self-disclosure tendencies as distance from a male experimenter decreased, while males in the same condition showed no difference in self-disclosure. Leibman (1970) theorized that females are socialized to be dependent, emotional, and capable of forming deep intimate relationships, and that such socialization should result in preferences for closer interpersonal distances for females than for males. Leibman's (1970) data indicated that females preferred closer distances to other females than to males, and that females stayed closer together than did males.

Freedman, Levy, Buchanan, and Price (1972) reported an interaction of sex of group with density such that female groups displayed more positive feelings and gave lighter sentences (mock jury task) when crowded than when uncrowded. Males showed the opposite effect. Ross, Layton, Erickson, and Schopler (1973), employing choice-dilemma problems, reported that males responded more favorably toward self and others in the uncrowded than in the crowded condition, while females responded in the opposite manner. Further, Stokols et al. (1973) failed to obtain a predic- 
ted interaction of room size (density) with sex of group, but weak support was obtained on other measures: Females were generally more comfortable and males were more dissatisfied with the physical environment in the small than in the large room. However, Marshall and Heslin (1975), employing orthogonal manipulations of group size, density, group sex composition, and sex of subjects, reported rather complex interactions (i.e., Group Size by Sex Composition; Density by Sex Composition). Males showed general positive feelings to mixed groups, but females were sensitive to a variety of factors. When females were in mixed-sex groups they preferred large groups to small, and crowded groups to uncrowded, but when they were in same-sex groups they preferred small groups and uncrowded groups.

Taken together, these studies suggest that females generally prefer closer interaction distances than males and females may be more sensitive to norms regarding spacing than are males. Thus, in the present study, it was hypothesized that females would prefer the close interaction distance to the far distance, but males would prefer the far to the close distance. No clear basis for prediction exists for the effect of sex of moderator since previous research examined here employed unmoderated groups exclusively. The present study initiated investigation of this factor.

\section{METHOD}

\section{Subjects and Design}

Subjects were 120 male and 120 female students from introductory psychology classes. Subjects participated in groups of three for a course requirement and credit points. Each group engaged in a $15-\mathrm{min}$ discussion of women's liberation. During the discussion, subjects sat on cushions strategically located and taped to the floor. For some groups the cushions were close together, for other groups they were far apart. Two males and two females served as moderators and constituted the variable "sex of moderator." Subjects were either all male or all female in each group, forming the "sex of subjects" variable. The design was thus a 2 by 2 by 2 factorial and was replicated for the second set of moderators. Groups of unacquainted subjects were randomly assigned to each of the eight conditions. The random factor for groups was nested in each condition and was included in the analysis. This permitted treating subjects as the sampling unit.

\section{Experimental Setting}

The experimental room was $7.5 \times 15 \mathrm{ft}$ in dimension, carpeted, and completely bare of furniture except for four cushions, each 14 in. square, taped to the floor. Prior to the subjects' arrival, the cushions were placed in the appropriate positions. Figure 1 shows the cushion locations for subjects and moderator for both distance conditions. There was a distance of $24 \mathrm{in}$. between the moderator's cushion (M) and the cushion for Subject B in the close condition, and a distance of 36 in. between cushions for Subjects $A$ and $C$. These placements put subjects quite close together, the nearest person being 6-12 in. away. Subjects in this condition were clearly in "intimate" interaction distance, but were not in physical contact.

Distances in the far condition were as follows: $M$ to B was $58 \mathrm{in}$. and $A$ to $C$ was 142 in. With a group sitting on the floor at these distances, a sense of spaciousness was created, but the

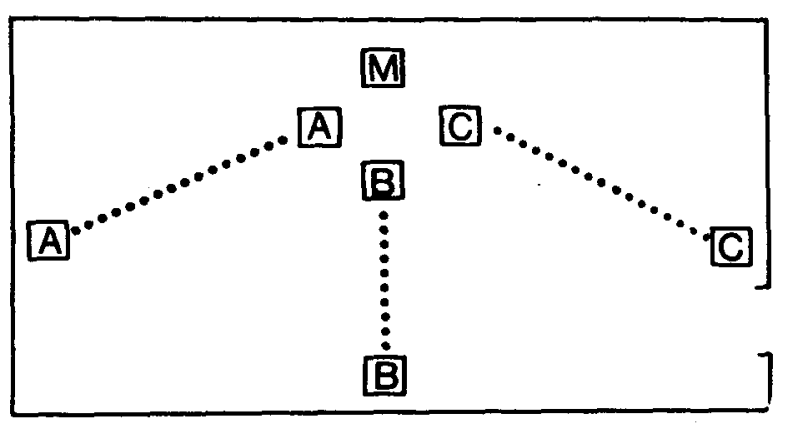

Figure 1. Position of moderator (M) and subjects (A, B, C) in the experimental room for both close and far seating conditions.

situation did not seem unnatural. Variation in interaction distance was considered to create a difference in density per fixed area of space.

\section{Procedure}

The moderator greeted the subjects in the waiting room and escorted them to the experimental room. After the subjects were seated, the moderator explained that the specific instructions were taped for control purposes and then played the instructions. The instructions (given by a male) indicated that the study was about group dynamics, interaction, situational factors on interaction processes, and impression. Subjects were thus oriented to the tasks of group discussion and forming impressions of the situation and the other discussants for subsequent rating purposes.

Following the instructions, introductions were exchanged and the group engaged in a 15-min discussion of women's liberation. The moderator's role was to keep the discussion moving by posing questions from a standardized list. An attempt was made to standardize the behavior of all moderators. They very carefully tried to minimize any cues as to how they felt about the situation and maintained a quiet, nonevaluative role. The topic was of sufficient interest to students that discussions were generally lively and interesting.

Discussion items included general impressions of women's liberation, the degree of permanence of the women's movement in our society, and so forth. After the discussion, rating forms were completed. It was stressed to the subjects that their ratings would remain anonymous. The subjects were allowed to move or sit wherever they wished while completing the ratings. To enhance the plausibility of the situation, the moderator also went through the motions of completing the ratings. Upon completion of the ratings, subjects were debriefed and dismissed.

\section{Rating Measures}

Several different measures were included: (a) Ratings of moods during the discussion were completed on the adjectives attentive, elated, drowsy, active, jittery, fearful, affectionate, comfortable, satisfied, nervous, angry, contented, skeptical, pleased, and tense. Each rating was made on a 9-point scale with endpoints labeled "very much" (9) and "not at all" (1). (b) Ratings of the subjects' general evaluations of the discussion situation were obtained. The ratings (each on a 9-point scale) included intellectual level of the discussion, satisfaction with the group situation, enjoyment in participating, compatibility of group members, productivity of the group, profitableness of the discussion, and willingness to participate in other extracurricular activities with the group. (c) There was also assessment of subjects' attitudes toward women's liberation. Five Likert-type items were used for this purpose, with five response categories 
ranging from strongly disagree to strongly agree. (d) Rating of how far apart subjects perceived they sat from each other was included as a manipulation check. (e) Ratings of each individual subject by each of the other two subjects were made on intelligence, knowledge of women's liberation, morality, adjustment, liking, and preference as a work partner. The moderator was also rated by subjects on these six items. Each rating was made on a 9-point scale.

\section{RESULTS}

Based on correlations among the measures obtained in this study and previous ones (Giesen \& Hendrick, 1974; Hendrick, Giesen, \& Coy, 1974), certain items were highly correlated with one another and largely uncorrelated with other items. Thus, highly intercorrelated items were summed to derive more stable measures. Results are reported on the basis of these derived measures with exceptions as indicated. The mood variables were as follows: "Attention" consisted of the sum of ratings for attentive and drowsy (reversed). "Anxiety" was the sum for jittery, fearful, nervous, and tense. "Positive emotions" was the sum of ratings for elated, active, affectionate, satisfied, contented, and pleased. "Group evaluation" was the sum of the eight items noted under $b$ in the description of the rating measures in the Method section. "Attraction to other subjects" was the sum of the six items noted in e in the description of the rating measures. Each subject's ratings of the other two subjects in his group were summed to obtain a single score for each subject. "Attraction to moderator" was the sum of the same six ratings of the discussion moderator. "Attitude on the issue" was the sum of the five attitude ratings.

The mean ratings were inspected initially for differences between the two moderators of each sex. Very few differences were evident, and, therefore, the data were combined across moderators of the same sex and analyzed as a Distance by Sex of Subjects by Sex of
Moderator by Nested Groups design. Means are given in Table 1, and $F$ ratios for significant effects are given in the text.

Ratings of how far apart subjects perceived they were seated during the discussion showed a main effect for distance $\left[\mathrm{F}(1,84)=260.21, \mathrm{MSe}_{1}=1.83, \mathrm{p}<.001\right]$ and an effect for groups $\left[\mathrm{F}(84,148)=1.39, \mathrm{MSe}_{2}=1.32\right.$, $p<.05]$. The close condition $(2.08)$ was perceived as significantly closer than the far condition (4.90), indicating the adequacy of the distance manipulation.

\section{Dependent Measures}

Several Distances by Sex of Moderator interactions were obtained on the summed mood measures. Attention ratings indicated a significant Distance by Sex of Moderator interaction $\left[\mathrm{F}(1,84)=9.74, \mathrm{MSe}_{1}=5.76\right.$, $\mathrm{p}<.003]$. Attention in female-moderated groups showed a decrease as distance increased (near $=15.87$, $\mathrm{far}=14.65$ ), while showing an increase in malemoderated groups (near $=15.17$, far $=15.88$ ). There was also a trend for female subjects to report more attention than males $[15.68$ vs. $15.10 ; F(1,84)=3.55$, $\left.\mathrm{MSe}_{1}=5.76, \mathrm{p}=.063\right]$. Anxiety ratings showed a trend for sex of moderator in that female-moderated groups reported more anxiety than male-moderated groups $\left[12.80\right.$ vs. $11.13 ; \mathrm{F}(1,84)=3.43, \mathrm{MSe}_{1}=48.67$, $\mathrm{p}=.068]$. Ratings of positive emotions showed no significant effects. Group evaluation ratings revealed a trend for an interaction of Distance by $\dot{S}$ ex of Moderator $\left[F(1,84)=3.13, \mathrm{MSe}_{1}=139.8, \mathrm{p}=.081\right]$ and a groups effect $\left[F(84,148)=1.40, \mathrm{MSe}_{2}=99.68, \mathrm{p}<.05\right]$. As distance increased, ratings were more positive for malemoderated groups (close $=49.02$, far $=51.20$ ), but more negative for female-moderated groups (close $=50.87$, far $=47.65$ ).

The attraction to other subjects measure also indicated a significant Distance by Sex of Moderator interaction $\left[F(1,84)=4.15, \mathrm{MSe}_{1}=120.18, \mathrm{p}<.05\right]$ and

Table 1

Means for Summed Measures

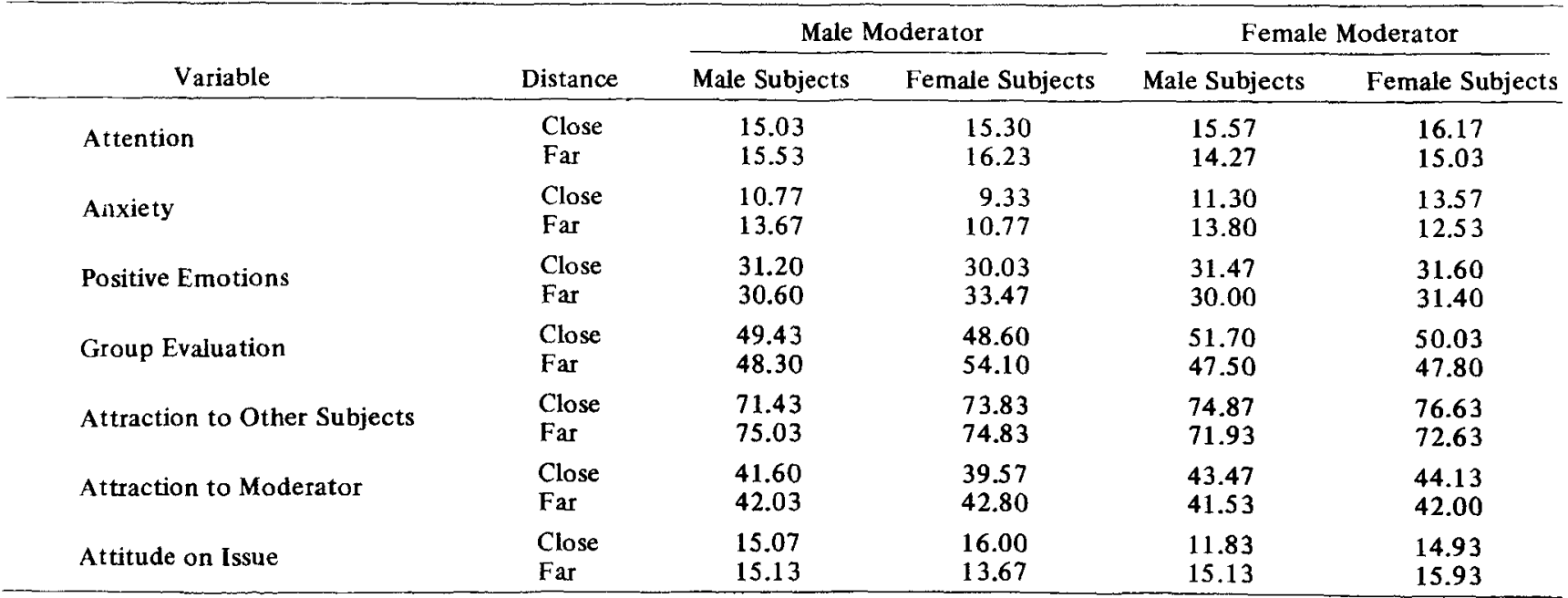


a groups effect $\left[\mathrm{F}(84,148)=1.40, \quad \mathrm{MSe}_{2}=85.76\right.$, $\mathrm{p}<.05]$. Again, as distance increased, greater attraction was indicated in male-moderated groups (close $=72.63$, far $=74.93$ ), while attraction decreased sharply in female-moderated groups $($ close $=75.75$, far $=72.28$ ).

The attraction to moderator measure similarly indicated a significant Distance by Sex of Moderator interaction $\left[\mathrm{F}(1,84)=7.15, \mathrm{MSe}_{1}=31.38, \mathrm{p}<.01\right]$. A less positive mean attitude was shown in the close (13.38) than in the far (15.53) condition for femalemoderated groups, but for male-moderated groups the attitude was more positive in the close (15.53) than in the far condition (14.40). The close vs. far difference for female-moderated groups was highly significant by Newman-Keuls test and marginally significant for the male-moderated groups.

Inspection of the individual cell means in Table 1 shows that male subjects sitting close together with a female moderator (11.93) were significantly less favorable in attitude than those sitting far away (15.13). However, when the moderator was a male, there was no difference between male subjects sitting close (15.07) or far away (15.13). There was a marginally significant trend for females in the close-male moderator condition (16.00) to be more favorable on the issue than females in the far-male moderator condition (13.67).

\section{DISCUSSION}

The results showed highly consistent interactive effects of physical interaction distance with sex of moderator on affective reactions, interpersonal evaluations, and attitude expression. However, these results may simply have been due to the degree of heterogeneity in sex composition of the groups. In order to examine this possible alternative explanation, all of the major dependent variables, attention through at titude, were reanalyzed using a 3 (sex composition) by 2 (distance) design. All-male, mixed-sex, and all-female groups made up the three levels of the first factor; and the two distances comprised the second factor. None of the main or interaction effects for the analyses were even marginally significant. Results for the contrasting analyses highlight the importance of treating moderator sex and subject sex as separate variables since these factors are confounded in a sex composition by distance design. Since sex heterogeneity of the groups failed as an explanation, the reported results can be discussed with greater confidence. Results for attitude expression are considered first.

\section{Attitude Expression}

The relatively negative attitude of males sitting close with a female moderator may have been due to a social facilitation effect (Zajonc, 1966). Dabbs (1971) found that close seating of males produced increased arousal as measured by sweat gland activity. McBride, King, and
James (1965) also reported increased arousal due to proximity. Normative attitude data collected early in the quarter indicated that male students felt slightly negative (14.42, $\mathrm{N}=330$ ) toward women's liberation, while females felt relatively positive $(16.00, N=345)$. The seating of males close to each other may have created a state of arousal which was, perhaps, further enhanced by the close seating to the female moderator. The enhanced arousal may have facilitated the males' dominant response tendency of negative feelings toward the issue, resulting in the lower attitude score.

A slightly different interpretation is that the close seating arrangement created a state of physiological arousal in the males which was interpreted as pleasant arousal because of the cognition of the near presence of an attractive female moderator (Walster \& Berscheid, 1971). Such pleasant arousal tendencies may have reinforced the male subjects' initial attitude on the issue, resulting in an even stronger attitude against women's liberation. There is some evidence that males sitting close to a female moderator were pleasantly aroused, relative to males sitting far away. Males sitting close to a female moderator rated themselves lower on anxiety and higher on attention, positive emotions, group evaluation, attraction to other subjects, and attraction to moderator than did males sitting far away.

\section{Evaluative Ratings}

Perhaps the most important result of this study is that the expected interaction of Distance by Sex of Subjects on evaluative ratings was not obtained. Instead, sex of moderator was a much more potent variable. In particular, sex of moderator interacted with distance on five of seven summed measures. Subjects, regardless of their own sex, had more favorable impressions of each other, the moderator, and the situation when seated close to a female moderator and far from a male moderator.

Strong corroborative evidence for the present results is provided by a recent study which examined crowding and sex of subject independent of sex of partner in dyadic interaction (Dabbs, Johns, \& Powell, Note 2). Persons responded more favorably when crowded by a female than by a male, regardless of their own sex. Another recent study of impression changes during group interaction has reported that interaction distance, sex of group, and sex of moderator are most important as interactive variables (Giesen \& McClaren, 1976). These studies and the present one provide strong evidence that distance and sex composition are indeed important factors deserving more careful study.

Although an attempt was made to minimize the status of the moderator in the present study, it seems that physical presence of the moderator defined the space norm for subjects. As noted earlier, previous research indicated that females tend to be approached more closely than males. It may be that subjects were 
placed so close to the male moderator that they felt they violated his personal space. However, if a smaller space zone existed for female moderators, then the close condition could have been relatively pleasant. Such differences in personal space zones between the sexes could largely account for the interactions involving distance and sex of moderator.

Another factor of importance is the status of the moderator. The moderator was implicitly of higher status than other group members. High status persons and group leaders generally help to define the formality of a given social situation (cf. Lott \& Sommer, 1967). The sex of the higher status person may be important. For example, expectations based solely on the information that a class was taught by a female rather than a male instructor would probably lead students to anticipate a less formal and more intimate class atmosphere, and perhaps closer seating would result between students and between students and the instructor. In the present study, a female moderator may have been perceived as somewhat lower in status than her male counterpart. Thus, closer seating would be more appropriate with a moderator more nearly of the subjects' status, resulting in relatively more positive reactions to female moderators in the close than in the far condition.

The present results and the Dabbs et al. (Note 2) study suggest a need to reevaluate previous research by Freedman and others in light of the following: (1) The sex of those with whom one is crowded seems to be a more important factor than one's own sex. (2) Studies of unmoderated groups are probably not directly comparable to studies of moderated groups since, for example, the former may be subject to the possible confounding effect of emerging leaders. (3) Finally, status of a group member, as well as the relationship of sex to perceived status, with regard to spatial norms and group evaluative reactions, need attention in future studies of interaction distance and crowding.

\section{REFERENCE NOTES}

1. Lett, E. E., Clark, W., \& Altman, I. A propositional inventory of research on interpersonal distance, 1969, Research Report No. 1, Naval Medical Research Institute.

2. Dabbs, J. M., Jr., Johns, C. J., \& Powell, P. H. Less eye contact when closer? Depends upon your partner's sex. Paper presented at the meeting of the American Psychological Association, Washington, D.C.. September, 1976.

\section{REFERENCES}

Argyle, M., \& Dean, J. Eye contact, distance and affiliation. Sociometry, 1965, 28, 289-304.
BAXTER, J. C. Interpersonal spacing in natural settings. Sociometry, 1970, 33, 444-456.

BYRNE, D. The influence of propinquity and opportunities for interaction on classroom relationships. Human Relations, $1961,14,63-69$.

Dabss, J. M., JR. Physical closeness and negative feelings. Psychonomic Science, 1971, 23, 141-143.

Dosey, M. A., \& Meisels, M. Personal space and selfprotection. Journal of Personality and Sacial Psychology, 1969, 11, 93-97.

Freedman, J. L., Klevansky, S., \& Ehrlich, P. R. The effect of crowding on human task performance. Journal of Applied Social Psychology, 1971, 1, 7.25.

Freedman, J. L., LeVy, A., Buchanan, R., \& Price, J. Crowding and human aggressiveness. Journal of Experimental Social Psychology, 1972, 8, 528-548.

Giesen, M., \& Hendrick, C. Effects of seating distance and room illumination on the affective outcomes of small group interaction. Social Behavior and Personality, 1974, 2, 87-96.

Giesen, M., \& MCClaren, H. A. Discussion, distance, and sex: Changes in impressions and attraction during small group interaction. Sociometry, 1976, 39, 60-70.

Hendrick, C., Giesen, M., \& Coy, S. The social ecology of free seating arrangements in a small group interaction context. Sociometry, 1974, 37, 262-274.

JoURARD, S. M., \& FrIEDMAN, R. Experimenter-subject "distance" and self-disclosure. Journal of Personality and Social Psychology, 1970, 15, 278-282.

LEIBMAN, $M$. The effects of sex and race norms on personal space. Environment and Behavior, 1970, 2, 208-246.

LotT, D. F., \& Sommer, R. Seating arrangements and status. Journal of Personality and Social Psychology, 1967, 7, 90-95.

Marshall, J. E., \& Heslin, R. Boys and girls together: Sexual composition and the effect of density and group size on cohesiveness. Journal of Personality and Social Psychology, 1975, 31, 952-961.

McBride, G., King, M. G., \& James, J. W. Social proximity effects on galvanic skin responses in adult humans. Journal of Psychology, 1965, 61, 153-157.

Mehrabian, A. Relationship of attitude to seated posture, orientation, and distance. Journal of Personality and Social Psychology, 1968, 10, 26-30.

Meisels, M., \& Guardo, C. J. Development of personal space schemata. Child Development, 1969, 40, 1167-1178.

Ross, M., Layton, B., Erickson, B., \& Schopler, J. Affect, facial regard, and reactions to crowding. Journal of Personality and Social Psychology, 1973, 28, 69-76.

Stokols, D., Rall, M.. Pinner, B., \& Schopler, J. Physical, social and personal determinants of the perception of crowding. Environment and Behavior, 1973, 5, 87-115.

WALSTER, E., \& BersCheID, E. Adrenaline makes the heart grow fonder. Psychology Today, June 1971, 62, 47-50.

WrLlis, F. N., JR. Initial speaking distance as a function of the speakers' relationship. Psychonomic Science, 1966, 5, $221-222$

ZAJONC, R. B. Social psychology: An experimental approach. Belmont, Calif: Brooks/Cole, 1966.

(Received for publication April 23, 1976; revision received June 28,1976 .) 